\title{
Bifunctional Metal Meshes Acting as Semipermeable Membrane and Electrode for Sensitive Electrochemical Determination of Volatile Compounds
}

Gabriela F. Giordano, ${ }^{\dagger, \#}$ Vitoria M. S. Freitas, ${ }^{\dagger, \$, \#}$ Gabriel R. Schleder, ${ }^{\dagger, \epsilon}$ Murilo Santhiago, ${ }^{\dagger, \epsilon}$ Angelo L. Gobbi, ${ }^{\dagger}$ and Renato S. Lima $*, \dagger, \$, €$

†Brazilian Nanotechnology National Laboratory, Brazilian Center for Research in Energy and Materials, Campinas, São Paulo 13083-970, Brazil

\$Faculty of Chemical Engineering, University of Campinas, Campinas, São Paulo 13083-970, Brazil

Institute of Chemistry, University of Campinas, Campinas, São Paulo 13083-970, Brazil

${ }^{\S}$ São Carlos Institute of Chemistry, University of São Paulo, São Carlos, São Paulo 09210-580, Brazil

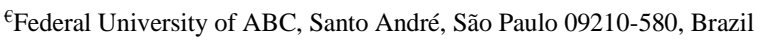

${ }^{*}$ Corresponding author: Renato Sousa Lima, e-mail: renato.lima@Innano.cnpem.br.

\section{Summary:}

1. Material and chemicals

2. Fabrication of the membrane-electrode meshes

3. Delimitation of the sensing area and modification of the Ni MEM with nanoparticles

4. Morphological characterization of MEMs

5. Hydrophilicity and oleophilicity of Ni meshes

6. Platform for gas diffusion extraction and electrochemical analysis of volatile analytes

7. Laser scanning confocal microscopy

8. Evaluation of the reverse diffusion of ethanol

9. Comparison with the literature

10. Machine Learning

11. Coating of the $40-\mu \mathrm{m}$ Ni meshes with Au by sputtering

12. Interference testing

13. Long-term monitoring

14. References 


\section{Material and chemicals}

AZ 50XT resist and developer AZ 400K was supplied by Microchemicals (Ulm, Germany) and Clariant (Muttenz, Switzerland), respectively. Sodium hydroxide ( $\mathrm{NaOH})$, ethanol, sodium nitrate, acetone, Extran MA02 Neutral, isopropanol, and potassium ferrocyanide $\left(\mathrm{K}_{4} \mathrm{Fe}(\mathrm{CN})_{6}\right)$ were supplied by Merck (Darmstadt, Germany). Nickel nitrate hexahydrate $\left(\mathrm{Ni}\left(\mathrm{NO}_{3}\right)_{2} \cdot 6 \mathrm{H}_{2} \mathrm{O}\right)$, cadmium nitrate tetrahydrate $\left(\mathrm{Cd}\left(\mathrm{NO}_{3}\right)_{2} \cdot 4 \mathrm{H}_{2} \mathrm{O}\right)$, and cobalt nitrate hexahydrate $\left(\mathrm{Co}\left(\mathrm{NO}_{3}\right)_{2} \cdot 6 \mathrm{H}_{2} \mathrm{O}\right)$ were purchased from Sigma-Aldrich (St. Louis, USA). Methylene blue (MB) and potassium ferricyanide $\left(\mathrm{K}_{3} \mathrm{Fe}(\mathrm{CN})_{6}\right)$ were purchased from Synth (Diadema, Brazil). The chrome etching solution and hexamethyldisilazane (HMDS) were purchased from Technic (Rhode Island, USA), whereas the gold etching solution was purchased from Degussa (Guarulhos, Brazil). The electroplating nickel brilliant and gold (Auruna 553) baths were supplied by Electrogalvano (Limeira, Brazil) and Coimpa (Manaus, Brazil), respectively. Glass substrates and Parafilm ${ }^{\circledR}$ M were acquired from Perfecta (São Paulo, Brazil) and Merck (Darmstadt, Germany), respectively. All solutions were prepared in deionized water (Milli-Q, Millipore Corp., Bedford, MA), obtained with resistivity of $18 \mathrm{M} \Omega \mathrm{cm}$.

The equipment used in the photolithographic steps in the clean room were $\mu$ PG101 direct laser writing by Heidelberg (Heidelberg, Germany), spinner by Headway Research (Garland, USA), MJB3 photoaligner from Karl Suss (Garching, Germany), and Dektak 150 Veeco optical profilometer supplied by Bruker (Billerica, USA). For the deposition of thin films by sputtering, Orion 8 Phase II-J from AJA International (North Scituate, USA) was used. DC power supply for electroplating nickel bath was an HP E3631A from Agilent Technologies (Saint Clare, USA). The equipment used for contact angle measurement was an Attension ${ }^{\circledR}$ Theta Lite optical tensiometer by Biolin Scientific (Västra Frölunda, Sweden). The characterization of the meshes was conducted by scanning electron microscopy with a Scientific Quanta 650 Field Emission Gun (SEM-FEG) from Thermo Fisher (Waltham, USA) and laser scanning confocal microscopy (LSCM) with a VK-X200 from Keyence (Itasca, USA). The concentration of ethanol was quantified by gas chromatography with flame ionization detection (GCFID), TRACE 1310 from Thermo Scientific (Waltham, EUA).

\section{Fabrication of the membrane-electrode meshes}

The membrane-electrode meshes (MEMs) of Ni were fabricated employing photolithography. First, it is needed to fabricate a pattern-transfer mask by direct laser writing. Three dark field masks were engraved, which presented a circular shape with diameter of $28 \mathrm{~mm}$ and an array of micropores with nominal diameters of 8,20 , and $40 \mu \mathrm{m}$. Molds were manufactured using $25-\mathrm{cm}^{2}$ glass as a substrate coated with metallic thin films of chrome $(\mathrm{Cr})$ and gold $(\mathrm{Au})$ showing 250 and $2000 \AA$ in thickness, respectively, via sputtering. Then, the metal-coated substrates were left to a soft bake on hot plate at $120{ }^{\circ} \mathrm{C}$ for $10 \mathrm{~min}$ for dehydration. The applications of HMDS and photoresist AZ50XT were performed by spin coating at a rotation of $4000 \mathrm{rpm}$ during $30 \mathrm{~s}$ for the HMDS and 2000 and $3400 \mathrm{rpm}$ during 20 and $5 \mathrm{~s}$, respectively, for the photoresist. The HMDS-coated slides were softbaked at $120^{\circ} \mathrm{C}$ for $10 \mathrm{~min}$. This process for the photoresist-coated slides relied on a ramp from 50 to $112^{\circ} \mathrm{C}$ for $30 \mathrm{~min}$. The exposure to ultraviolet light (UV) was conducted in the photoaligner during $150 \mathrm{~s}$ under a power of $9.5 \mathrm{~mW} \mathrm{~cm}^{-2}$. Following, the photoresist development was made in AZ K400 1:3 v/v in solvent for approximately $2.5 \mathrm{~min}$. The photoresist film thickness was around $25 \mu \mathrm{m}$ according to the optical profilometer.

The electrochemical growth of Ni was made in an electroplating bath. The dc power supplier provided a current of $250 \mathrm{~mA}$ for $60 \mathrm{~min}$, while cycling washes with deionized water every $15 \mathrm{~min}$. The resulting Ni film reached a thickness of roughly $20 \mu \mathrm{m}$. The photoresist was removed by immerging the substrate in acetone. After this step, the excesses of $\mathrm{Cr}$ and $\mathrm{Au}$ were removed from the Ni meshes after dipping into their respective etching 
bathes. Finally, the achieved MEM was washed with Extran ${ }^{\circledR}$ and isopropanol, followed by drying with nitrogen flow. The steps of this procedure are briefly illustrated in Figure S1A.

The stainless-steel wire meshes (SSWMs) consisted of commercial screen-printed meshes that was cut to the proper format (square with 20-mm side size) and cleaned with Extran ${ }^{\circledR}$ and isopropanol. This MEM is shown in Figure S1B. To add flexibility to the method, we coated 40- $\mu \mathrm{m}$ Ni MEMs and SSWMs with Au films by electrodeposition and sputtering, respectively. The electrodeposition was conducted in electrochemical bath at $65{ }^{\circ} \mathrm{C}$ under a current density of $0.3 \mathrm{~A} \mathrm{dm}^{-2}$ for $10 \mathrm{~min}$. The thin films deposited by sputtering were $\mathrm{Cr}$ followed by Au presenting 500- and 2500- $\AA$ thickness, respectively.
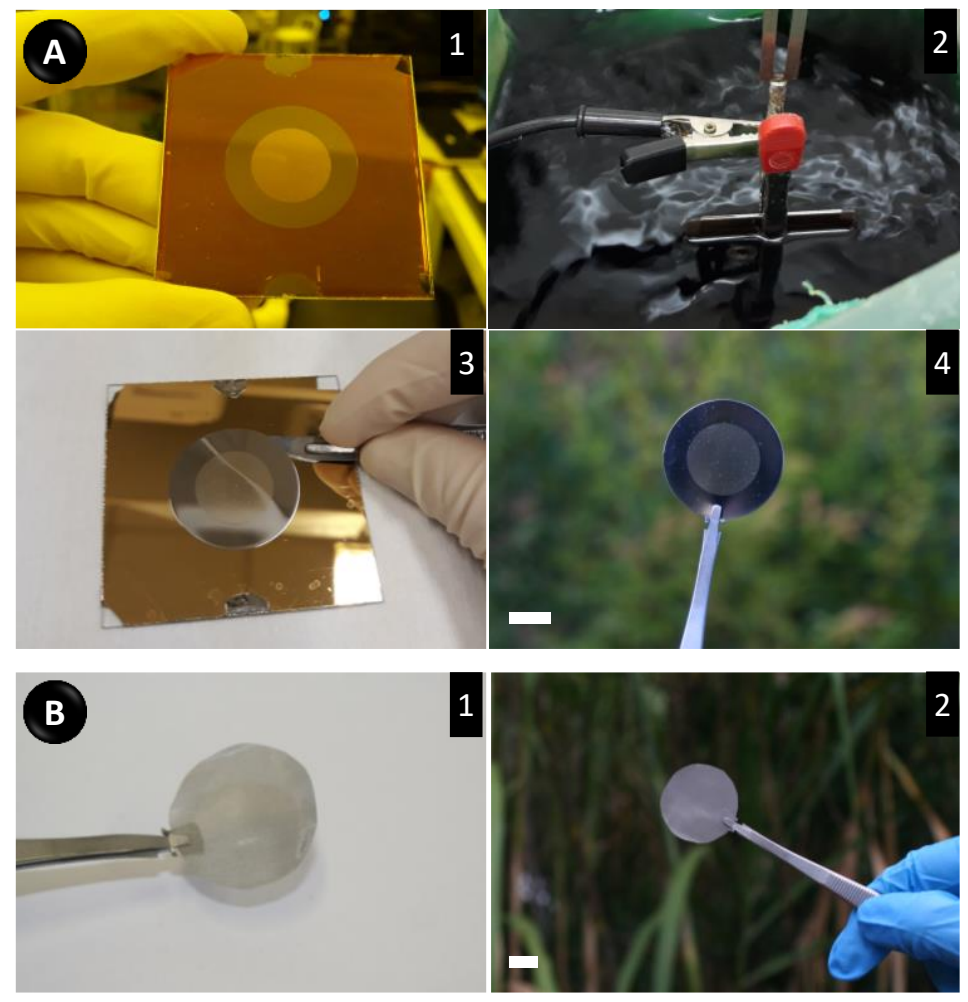

Figure S1. (A) Ni MEM manufacturing process. (1) Mold after UV exposure, (2) bath for Ni electroplating, (3) removal of mesh from substrate, and (4) Ni MEM after cleaning. (B) Photos of the SSWM after cutting and cleaning $(1,2)$. The scale bars mean $10 \mathrm{~mm}$

\section{Delimitation of the sensing area and modification of the Ni MEM with nanoparticles}

The area of the MEMs exposed to receptor electrolyte, i.e., the electrodic area, was delimited by Parafilm ${ }^{\circledR}$. The latter and a transparent adhesive tape were cut with the aid of a circular drill with 5-mm diameter and applied to the mesh. For adhesion of these layers on $\mathrm{Ni}$, this stack was heated at $120{ }^{\circ} \mathrm{C}$ for $12 \mathrm{~min}$. For ethanol detection, the sensing area of the Ni MEM was modified with nanoparticles of $\mathrm{Ni}(\mathrm{OH})_{2}$. In alkaline medium, $\mathrm{Ni}(\mathrm{OH})_{2}$ is reversibly oxidized to the high-valence $\mathrm{NiOOH}$ that acts as an electron mediator in the irreversible oxidation of various organic compounds as follows, respectively:

$$
\begin{aligned}
& \mathrm{Ni}(\mathrm{OH})_{2(s)}+\mathrm{OH}^{-} \rightarrow \mathrm{NiOOH}_{(\mathrm{s})}+\mathrm{H}_{2} \mathrm{O}+\mathrm{e}^{-} \\
& \mathrm{NiOOH}+\text { org } \rightarrow \mathrm{NiOOH}(\text { org })_{(\text {ads })} \rightarrow \mathrm{NiOOH}+\text { products }+\mathrm{H}^{+}+\mathrm{e}^{-}
\end{aligned}
$$

(Equation 2) 
$\mathrm{NiOOH}$ is able to oxidize species such as alcohols, ${ }^{1,2}$ carbohydrates,${ }^{3}$ amino acids,${ }^{4}$ and insulin. ${ }^{5} \mathrm{Ni}(\mathrm{OH})_{2}$ exists as four structural phases, $\alpha-\mathrm{Ni}(\mathrm{OH})_{2}, \beta-\mathrm{Ni}(\mathrm{OH})_{2}, \beta-\mathrm{NiOOH}$, and $\gamma-\mathrm{NiOOH}$. While the $\alpha$ phase shows the highest catalytic action, it is unstable undergoing chemical conversion to $\beta-\mathrm{Ni}(\mathrm{OH})_{2}$ after continuous processes of charge and discharge and over the material ageing. According to Vidotti et al., ${ }^{4}$ one strategy to stabilize $\alpha-\mathrm{Ni}(\mathrm{OH})_{2}$ concerns the use of other metal ions as additives in the $\mathrm{Ni}(\mathrm{OH})_{2}$-based electrode construction, e.g., cobalt $\left(\mathrm{Co}^{2+}\right)$ and cadmium $\left(\mathrm{Cd}^{2+}\right)$ ions. Such procedure was applied in this work through the cathodic electrodeposition of Ni, Co, and Cd hydroxides ${ }^{1}$ by applying a cathodic current density of $-1.27 \mathrm{~mA} \mathrm{~cm}^{-2}$ in $10.0 \mathrm{mmol} \mathrm{L}^{-1}$ solution of $\mathrm{Ni}, \mathrm{Co}$, and $\mathrm{Cd}$ nitrates under the v/v proportions of $77 \%, 20 \%$, and $3 \%$, respectively. Such nitrates were prepared in $20 \mathrm{mmol} \mathrm{L}^{-1}$ sodium nitrate solution. The current was applied during $20 \mathrm{~s}$. Then, the electrode was immersed in $100 \mathrm{mmol} \mathrm{L}^{-1} \mathrm{NaOH}$ solution for $15 \mathrm{~min}$. Finally, 30 cycles of cyclic voltammetry were performed. 


\section{Morphological characterization of MEMs}
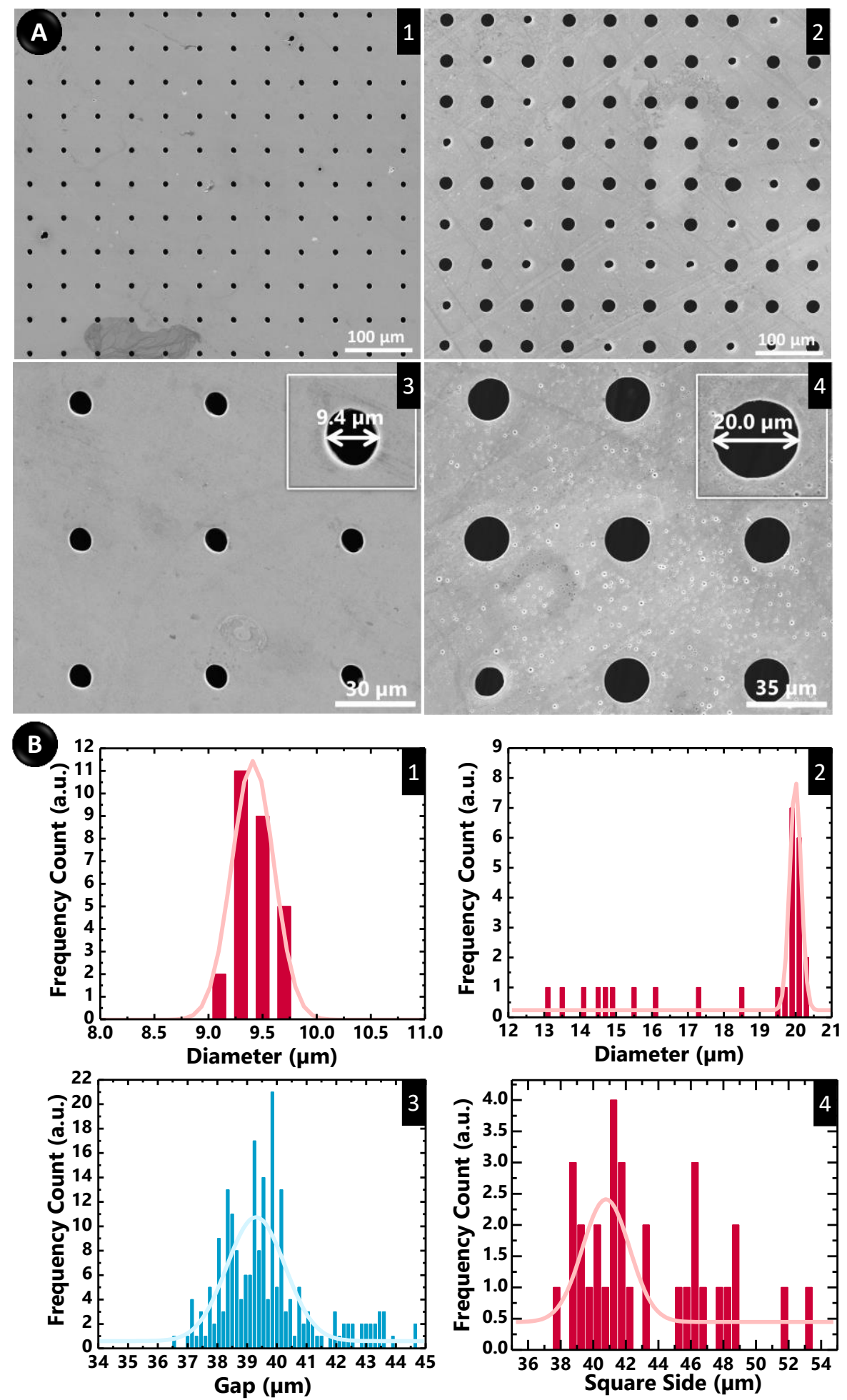

Figure S2. (A) SEM images of Ni MEMs with nominal pore diameters of 10 (1-3) and $20 \mu \mathrm{m}$ (2-4). (B) Distributions of pore sizes for Ni MEM bearing nominal diameters of 10 (1) and $20 \mu \mathrm{m}$ (2), distribution of total hole gaps for Ni MEM (3), and distribution of square side sizes for SSWM (4). The lines correspond to gaussian fittings. 


\section{Hydrophilicity and oleophilicity of Ni meshes}

For heterogeneous composite wetting states as observed in the $\mathrm{Ni}$ and stainless-steel meshes, the contact angle can be described by the Cassie-Baxter equation:

$$
\cos \theta_{\mathrm{C}}=\mathrm{f}_{\mathrm{SL}} \cos \theta_{1}+\mathrm{f}_{\mathrm{SW}} \cos \theta_{2}
$$

In which $\mathrm{f}_{\mathrm{SL}}$ is the percentagem of the solid contact surface to the apparent total contact área of the unit, $\mathrm{f}_{\mathrm{SW}}$ is the percentagem of the gas-liquid contact surface to the apparent total contact área, $\theta_{1}$ is the contact angle of the liquid on the ideal smooth solid surface, and $\theta_{2}$ is the liquid contact angle at the ideal air surface. ${ }^{6} \mathrm{~A}$ convex menisci inside the holes but filling up only a portion of their depths is expected to be formed as illustrated in Figure S3. This phenomenon is noted when the surface tension of liquid is larger than the interfacial tension of liquid-solid substrate.

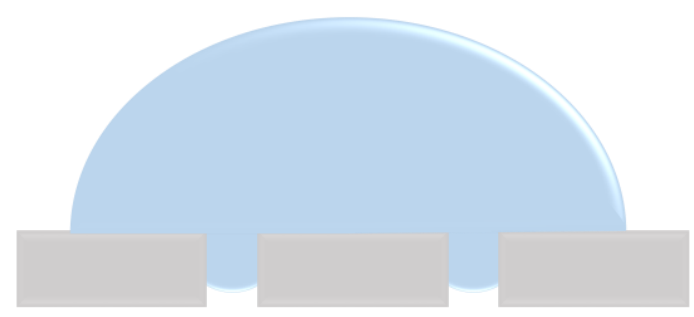

Figure S3. Illustration of the convex menisci that is supposed to be observed inside the holes of the Ni MEM with nominal pore diameters of 10 and $20 \mu \mathrm{m}$. In these cases, the water fills just a portion of the hole depths, implying the liquid surface tension is higher than the interface tension between liquid and the hole walls.

Video S1. Drops of n-hexane passing through 40- $\mu \mathrm{m}$ Ni mesh demonstrating its oleophilic character. This result shows the surface tension of liquid is lower than the interface tension between n-hexane and the hole walls of $\mathrm{Ni}$. 


\section{Platform for gas diffusion extraction and electrochemical analysis of volatile analytes}

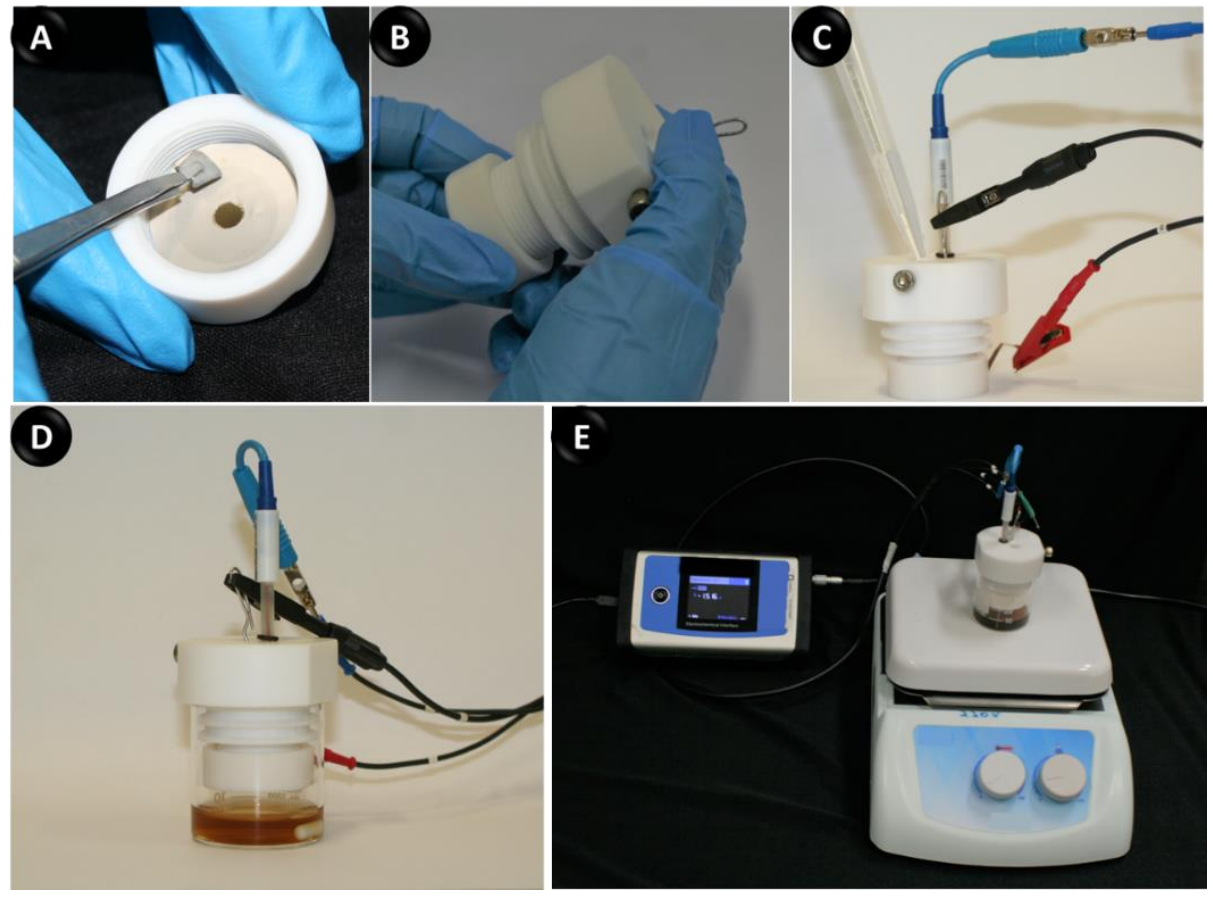

Figure S4. (A) Placing the MEM into the bottom part of PTFE module. (B) Locking the top and bottom parts of this module. (C) Addition of electrolyte (receptor solution) with the aid of a volumetric micropipette. (D) PTFE module with electrodes and electrolyte on the donor sample-containing flask. (E) Analytical platform comprising also potentiostat and magnetic stirrer for the measurements. 


\section{Laser scanning confocal microscopy}

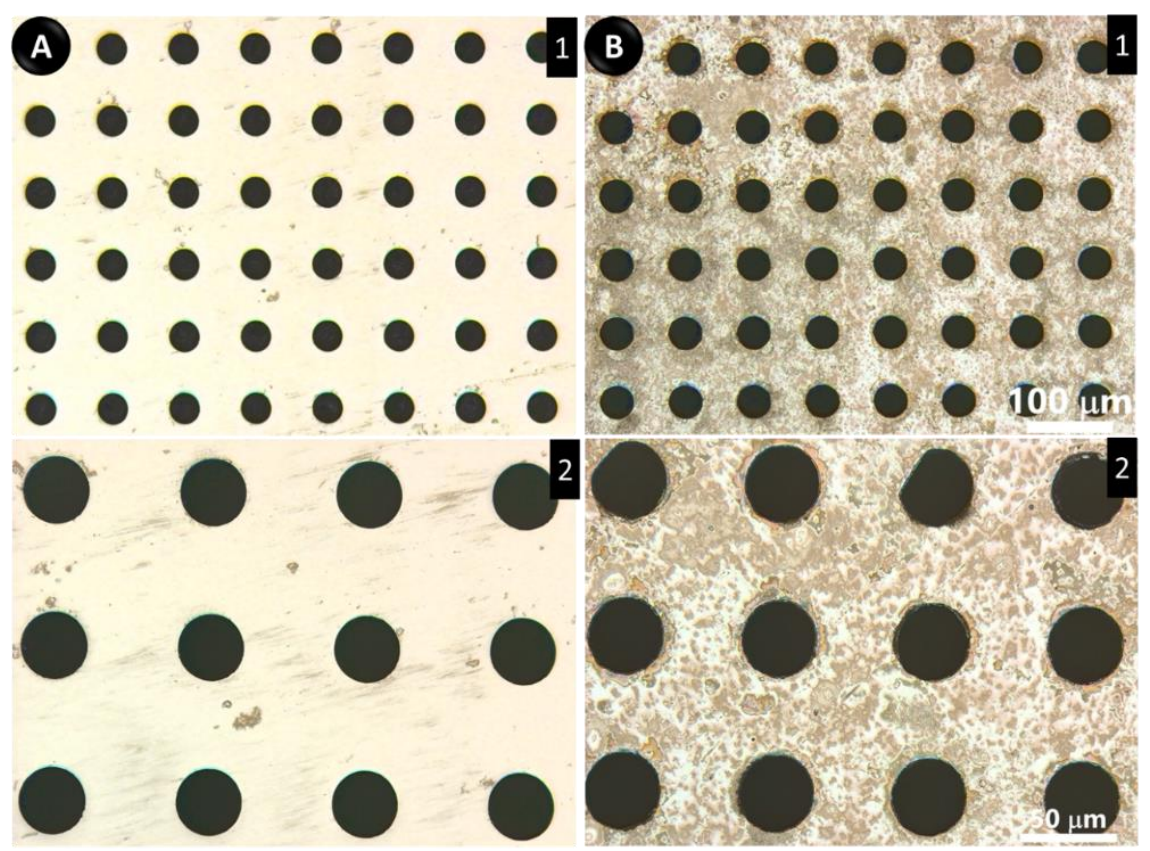

Figure S5. Topography images by LSCM of 40- $\mu \mathrm{m}$ Ni meshes: (A) bare mesh $(1,2)$ and (B) mesh modified with nanoparticles of $\mathrm{Ni}(\mathrm{OH})_{2}(1,2)$.

\section{Evaluation of the reverse diffusion of ethanol}
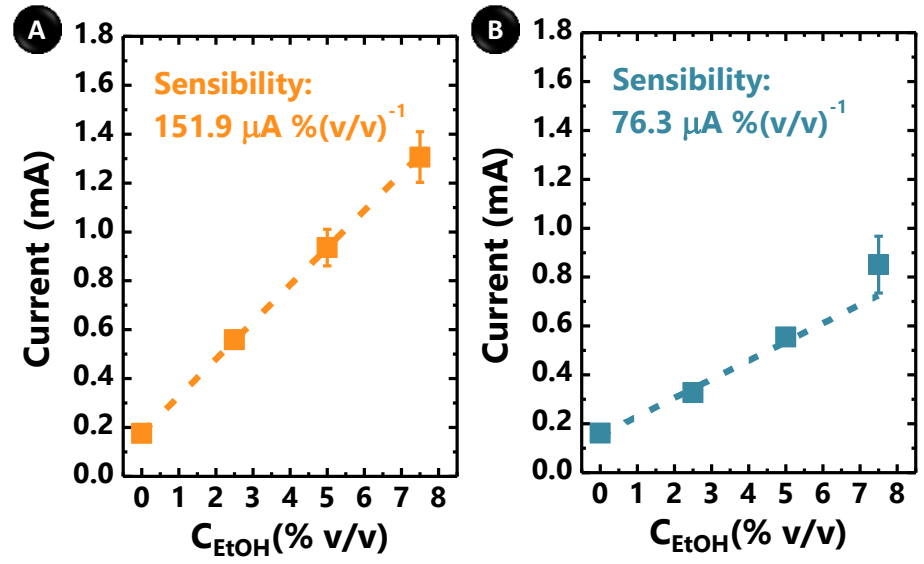

Figure S6. Individual analytical curves obtained from the second (A) and fourth (B) scans of cyclic voltammetry-based assays after interrupting the contact between the vapors from donor solutions and the PTFE module. $\mathrm{C}_{\mathrm{EtOH}}$ means the concentration of ethanol. 

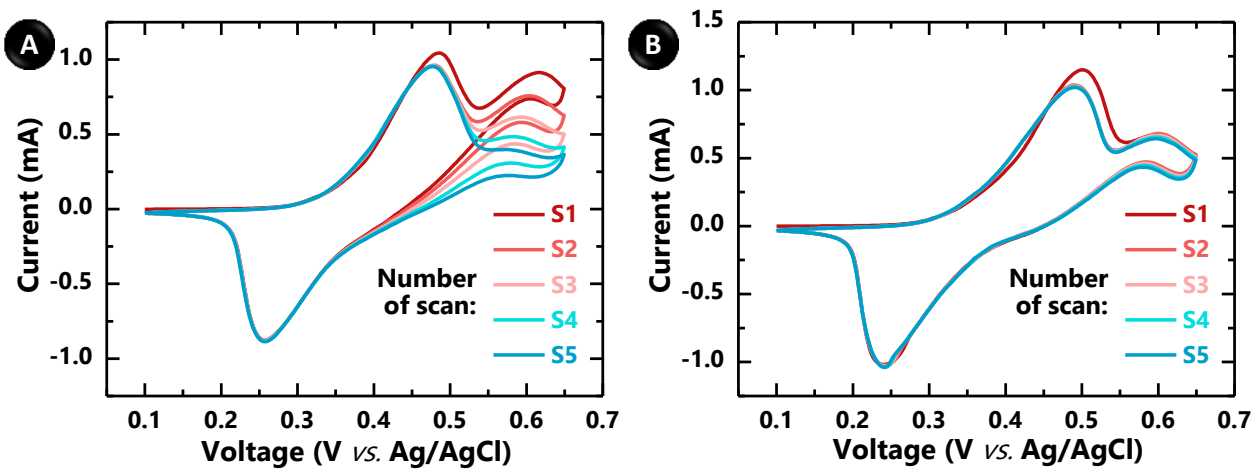

Figure S7. Cyclic voltammograms (A) without and (B) with the donor solution below the MEM-receptor during the analyses to ethanol. $\mathrm{C}_{\mathrm{EtOH}}$ in donor phase was $2.5 \%$ (A) and $0.3 \% \mathrm{v} / \mathrm{v}(\mathbf{B})$. When performing the detection in the absence of donor, the currents decreased gradually over the subsequent scans (S), while the responses in the presence of donor remained constant.

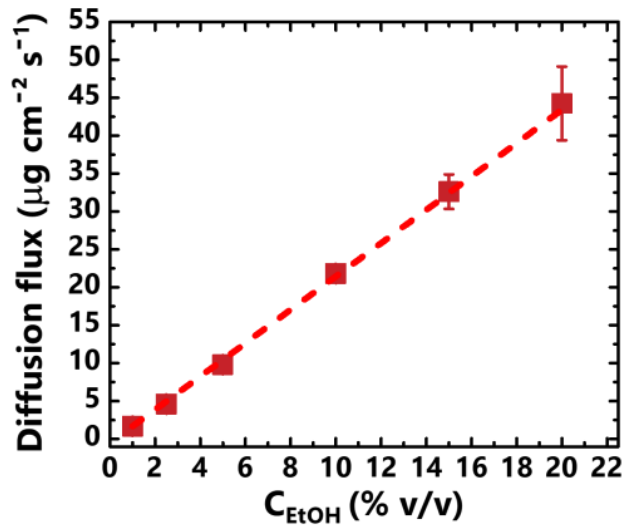

Figure S8. Diffusion flow of ethanol vapor through 40- $\mu \mathrm{m} \mathrm{Ni} \mathrm{MEM} \mathrm{as} \mathrm{a} \mathrm{function} \mathrm{of} \mathrm{C}_{\mathrm{EtOH}}$ in donor phase. These values were obtained from the analyses of samples collected by GC-FID (see the discussion in the main text).

\section{Comparison with the literature}

Table S1. Limits-of-detection (LOD) achieved for ethanol in alcoholic beverages and fermentation broths using gas diffusion extraction-based approaches ${ }^{\dagger}$

\begin{tabular}{lccc}
\hline Method & Sample & LOD $(\%$ v/v) & Reference \\
\hline FA/TBS-GD-AOD reactor-amperometry & Beer/Wine & 0.0001 & {$[7]$} \\
FIA-GD-amperometry on copper oxide electrode & Alcoholic beverages & 0.4 & {$[8]$} \\
FIA-GD-spectrophotometry & Alcoholic beverages & 0.03 & {$[9]$} \\
FIA-GD-spectrophotometry & Wine/Molasses & 0.18 & {$[10]$} \\
SIS-GD-ADH-spectrophotometry & Wine & 0.05 & {$[11]$} \\
GD-voltammetry-Ni(OH)2-bulk electrode & Fermentation broth & 0.18 & {$[1]$} \\
FIA-GD-CCD detector & Alcoholic beverages & 0.6 & {$[12]$} \\
MGD-RFI-colorimetry & Alcoholic beverages & 0.62 & {$[13]$} \\
Flow system-GD-spectrophotometry & Alcoholic beverages and & 2.23 & {$[14]$} \\
GD-voltammetry-MEM & herbal medicines & & This work
\end{tabular}

†GD: gas diffusion; FA/TBS: flow analysis with time-based sampling; FIA: flow injection analysis; AOD: alcohol oxidase; ADH: alcohol dehydrogenase; SIS: sequential injection system; CCD: charge-coupled device; MGD-RFI: membraneless gas diffusion with reverse flow injection. 
Several sensors for monitoring volatile organic compounds (VOCs) have been reported in the literature, including chemiresistive, electrochemical, and optical sensors as it can be seen in Table S2. These systems show different working ranges, including short ranges such as 10 to $50 \mathrm{ppm}$ of methanol ${ }^{14}$ and wide ranges covering, for instance, 4 orders of magnitude, i.e., $10^{-3}$ up to $10 \mathrm{ppm}$ of toluene. ${ }^{19}$ Concerning our platform, it was able to cover a range of 1 order of magnitude in ethanol concentration (790 to $7900 \mathrm{ppm})$. Nonetheless, further studies for evaluating the limit-of-linearity of the method still need to be performed. In terms of LOD, the value obtained for ethanol by our platform is lower than one recently reported in the literature using microneedles modified with alcohol oxidase enzyme as detailed in the table. ${ }^{23}$ The reasons for the high detectability of our sensing platform are discussed in the main text.

Further, most of the previously reported systems lack of application to real samples and involve a complex fabrication and benchtop instrumentation. In addition, these methods commonly require the use of $\mathrm{N}_{2}$ gas from standard cylinders as carrier gas or fluid for carrying analyte in synthetic samples, impairing the development of point-of-use sensing platforms. Otherwise, our system meets the requirements for this type of platform by involving a user-friendly and fast analysis along with the employment of a portable instrumentation. The method was also able to quantify volatile species in complex samples without sample-induced MEM contamination. One should highlight our method is commercially viable as well. While the Ni MEMs are fabricated by reproducible, scalable, and well-established techniques, the SSWMs are widely available at a low cost for purchase. 
Table S2. Analytical performance of different methods for VOC detection ${ }^{\dagger}$

\begin{tabular}{|c|c|c|c|c|c|c|c|c|c|}
\hline Sensing method & Sensor description & Target VOC & Sample & $\begin{array}{c}\text { Concentration } \\
\text { range }\end{array}$ & LOD & Response time & $\begin{array}{c}\text { Easy to } \\
\text { fabricate }\end{array}$ & Portability & Reference \\
\hline $\begin{array}{l}\begin{array}{l}\text { Electrical conductance } \\
\text { (current change) }\end{array} \\
\end{array}$ & Graphene/MoS 2 nanocomposite & Methanol & $\begin{array}{l}\text { Analyte gas synthetic } \\
\text { mixture with } \mathrm{N}_{2}\end{array}$ & $10-50 \mathrm{ppm}$ & N.I. & $210 \mathrm{~s}$ & Yes & No & {$[15]$} \\
\hline SAW resonators & $\begin{array}{c}\text { Biosensor composed of an array } \\
\text { of five SAW resonators coated } \\
\text { with three types (OBPs) }\end{array}$ & Octenol, carvone & $\begin{array}{l}\text { Analyte gas synthetic } \\
\text { mixture with } \mathrm{N}_{2}\end{array}$ & $\begin{array}{l}13 \mathrm{ppm} \text { to } 61 \mathrm{ppm} \text { for } \\
\text { octenol and } 9 \mathrm{ppm} \text { to } \\
43 \mathrm{ppm} \text { for carvone }\end{array}$ & $\begin{array}{c}0.48 \mathrm{ppm} \text { for } \\
\text { octenol and } 0.74 \\
\text { ppm for carvone }\end{array}$ & $95 \mathrm{~s}$ & No & No & [16] \\
\hline Chemiresistive & $\mathrm{PANI} / \mathrm{SnO}_{2}$ in PET substrates & Amonia & $\begin{array}{l}\text { Analyte gas synthetic } \\
\text { mixture with } \mathrm{N}_{2}\end{array}$ & $10-100$ ppm & $\geq 1.8 \mathrm{ppm}$ & $30 \mathrm{~s}$ & No & No & {$[17]$} \\
\hline Chemiresistive & MOS gas sensor & $\begin{array}{l}\text { Ethanol, } \\
\text { methanol, and } \\
\text { acetone }\end{array}$ & $\begin{array}{c}\text { Synthetic mixture of } \\
\text { each individual } \\
\text { analyte with air in } \\
\text { acrylic box } \\
\end{array}$ & $250-4000 \mathrm{ppm}$ & N.I. & $150 \mathrm{~s}$ & Yes & No & {$[18]$} \\
\hline Chemiresistive & $\begin{array}{l}\text { Sensing microchannels based on } \\
\text { incorporation of MWCNT in } \\
\text { polymers nanofiber by } \\
\text { electrospun }\end{array}$ & Acetone, toluene & Breath & $\begin{array}{l}3.510^{-2}-3.010^{0} \mathrm{ppm} \\
\text { for acetone and } 110^{-3} \\
-10 \mathrm{ppm} \text { for toluene }\end{array}$ & N.I. & $7.8 \mathrm{~s}$ & Yes & Yes & [19] \\
\hline Chemiresistive & $\begin{array}{c}\text { Inkjet-printed composite sensors } \\
\text { made by polymers and carbon } \\
\text { black }\end{array}$ & $\begin{array}{l}\text { Pentane, heptane, } \\
\text { acetone }\end{array}$ & $\begin{array}{l}\text { Analyte gas synthetic } \\
\text { mixture with } \mathrm{N}_{2}\end{array}$ & $\begin{array}{c}1.210^{4}-3.110^{4} \mathrm{ppm} \\
\text { pentane }\end{array}$ & N.I. & $30 \mathrm{~s}$ & Yes & No & {$[20]$} \\
\hline $\begin{array}{l}\text { Optical (refractive index } \\
\text { difference) }\end{array}$ & $\begin{array}{l}\text { Hybrid photonic - MOF } \\
\text { structure }\end{array}$ & $\begin{array}{c}\text { Methanol, } \\
\text { propylene, } \\
\text { benzene, toluene, } \\
\text { styrene } \\
\end{array}$ & $\begin{array}{l}\text { Analyte gas synthetic } \\
\text { mixture with } \mathrm{N}_{2}\end{array}$ & N.I. & $\begin{array}{c}58,29,35,76,99 \\
\text { ppm }\end{array}$ & $30 \min$ & No & No & [21] \\
\hline Optical (fluorescence) & $\begin{array}{l}\text { Optical-fiber probe employing } \\
\text { an ADH enzyme membrane }\end{array}$ & Ethanol & Skin volatiles & $110^{-3}-3.110^{0} \mathrm{ppm}$ & $2.510^{-2} \mathrm{ppm}$ & $6 \min$ & No & No & [22] \\
\hline Electrochemical & $\begin{array}{c}\text { Microneedles modified with } \\
\text { AOx enzyme }\end{array}$ & Ethanol & $\begin{array}{c}\text { Synthetic interstitial } \\
\text { fluid }\end{array}$ & $0-3685 \mathrm{ppm}$ & $230 \mathrm{ppm}$ & $30 \mathrm{~s}$ & No & Yes & {$[23]$} \\
\hline Electrochemical & $\begin{array}{l}\text { Nafion- RTIL modified planar } \\
\text { interdigitated electrode platform }\end{array}$ & Methanol & $\begin{array}{l}\text { Analyte gas synthetic } \\
\text { mixture with } \mathrm{N}_{2}\end{array}$ & $1-1000$ ppm & $1 \mathrm{ppm}$ & $5 \mathrm{~s}$ & No & No & {$[24]$} \\
\hline Electrochemical & Bifunctional Ni Meshes & Ethanol/ $\mathrm{HCl}$ & $\begin{array}{c}\text { Sugarcane } \\
\text { fermentation broths } \\
\text { (ethanol) }\end{array}$ & $\begin{array}{l}790-7900 \mathrm{ppm} \\
\text { ethanol }\end{array}$ & 60 ppm ethanol & $5-10 \mathrm{~min}$ & Yes & Yes & This work \\
\hline
\end{tabular}

†SAW: Surface acoustic wave; OBP: odorant-binding proteins; PANI: polyaniline; PET: polyethylene terephthalate; MOS: metal oxide semi-conductor; MWCNT: multiwalled carbon nanotube; MOF: metalorganic framework; ADH: alcohol dehydrogenase; AOx: alcohol oxidase; RTIL: room temperature ionic liquid; N.I.: not informed. 


\section{Machine Learning}

Machine learning (ML) is defined as a class of methods for automated data analysis that are capable of detecting patterns and/or correlations between responses within a set of data. ${ }^{25}$ The resulting model can predict unknown data and support decision-making processes. Herein, the supervised learning algorithm called as sure independence screening and sparsifying operator (SISSO) was used to learn and identify simple mathematical equations comprising selected currents from the second half of the CV voltammograms (tied to the NIOOHmediated oxidation of ethanol) as input data for delivering high-accuracy quantification of the amount of ethanol in fermentation broth samples. The expected output outcomes were the concentrations of ethanol, $\mathrm{C}_{\mathrm{EtOH}}$, obtained by GC-FID.

Recently described in the literature to evaluate material properties, ${ }^{26-28}$ SISSO is able to assure accurate predictions even from a small number of samples by using $\ell_{0}$-norm regularized optimization, thus ensuring a small number of nonzero components. This method combines the primary features (input data, i.e., currents from $\mathrm{CV}$ data in our case) into mathematical operations toward robust predictions from the smallest possible number of features. For this purpose, SISSO searches for the best low-dimensional descriptors (equations) to perform ML tasks from linear regressions. These simple mathematical equations have been successfully used in our group for high-performance analyses via electrochemical sensors. ${ }^{28,29}$

In this work, SISSO was applied in single-task mode. For model construction, we divided all the data (scans and replicates, totaling 195 different features) into two different data sets, training and test sets at a ratio of 93:7, respectively. The equation that best fitted the relationship between outputs and inputs in a linear model, as described in the main text of this article, generated three constant and dimensionless coefficients, namely, 7.12 $\left(\mathrm{c}_{1}\right),-6.26\left(\mathrm{c}_{2}\right)$, and $-1.0310^{-2}\left(\mathrm{c}_{3}\right)$.

\section{Coating of the 40- $\mu \mathrm{m}$ Ni mesh with Au by sputtering}

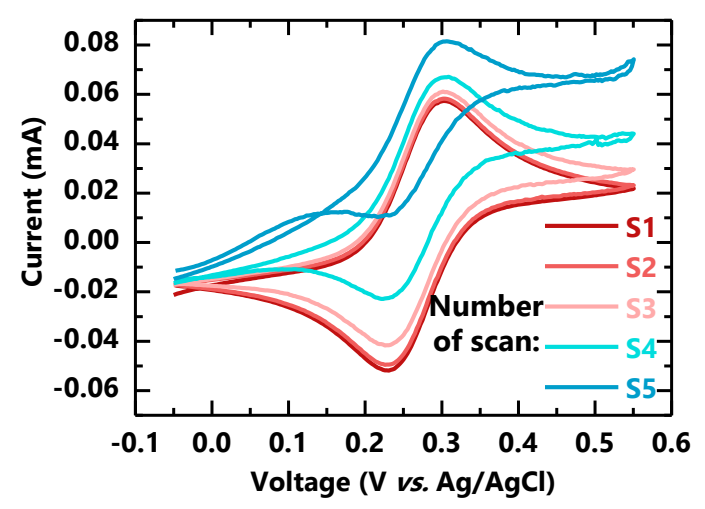

Figure S9. Sequential scans (S) to $2.0 \mathrm{mmol} \mathrm{L}^{-1}\left[\mathrm{Fe}(\mathrm{CN})_{6}\right]^{4-/ 3-}$ using Ni MEM coated with Au film by sputtering as working electrode. The reversibility of the system was disturbed from S3, indicating interaction of the probe with Ni and, then a nonconformal coating of the mesh by the thin film of Au.

\section{Interference testing}

It is well known that $\mathrm{Ni}(\mathrm{OH})_{2} / \mathrm{NiOOH}$ electrodes have high catalytic activity toward the irreversible oxidation of various organic species, ${ }^{1}$ e.g., alcohols, ${ }^{2,30}$ carbohydrates,${ }^{31}$ amino acids, ${ }^{4}$ and insulin. ${ }^{5}$ Conversely, these compounds only affect the performance of our platform (based on the Ni MEM modified with $\mathrm{Ni}(\mathrm{OH})_{2}$ nanoparticles) if they are capable of reaching the receptor solution to undergo redox reactions on the electrode 
surface, i.e., if they are volatile. To confirm this feature, we studied the effect of two compounds over the current after their addition in the receptor and donor phases. Such compounds were a volatile and a non-volatile specie, i.e., methanol and glucose, respectively. Typical voltammograms and the resulting current data $(+0.65 \mathrm{mV})$ are presented in Figure S10. The addition of $5.0 \mathrm{mmol} \mathrm{L}^{-1}$ glucose in the receptor phase $\left(0.1 \mathrm{~mol} \mathrm{~L}^{-1} \mathrm{NaOH}\right)$ led to a current response that was roughly 4 times higher than the blank current $\left(\mathrm{NaOH} 0.1 \mathrm{~mol} \mathrm{~L}^{-1}\right)$. However, the signal recorded when adding this analyte in the donor phase was similar to the blank current, showing that nonvolatile interferents are not able to disturb the response of our gas diffusion-based platform, as expected.

Concerning the volatile compound, methanol, it was added in donor phase at a concentration of $0.5 \% \mathrm{v} / \mathrm{v}$. In this case, the current signal was 9-fold higher than the blank current, corroborating the catalytic activity of our electrode toward the oxidation of this organic compound. We also conducted two other tests by keeping methanol $(0.5 \% \mathrm{v} / \mathrm{v})$ in donor phase, while adding glucose in this same phase at two concentrations, 5.0 and $10.0 \mathrm{~g} \mathrm{~L}^{-1}$ that are typically found in 20-times diluted sugarcane fermentation broths. ${ }^{32}$ The resulting current responses were similar to those ones reached in the absence of glucose (variation of only $0.8 \%$ ), showing that only methanol contributed to these signals. This result once again demonstrates the performance of our platform is not altered by non-volatile interferents. One should emphasize methanol is not found in sugarcane broths and, therefore this interference was not presented in our analyses to ethanol. The interference by volatile organic compounds could be solved using different mesh coatings that can selectively provide redox transformations of the analytes. For instance, some coatings have been proposed for the electro-oxidation of methanol and ethanol. ${ }^{33,34}$
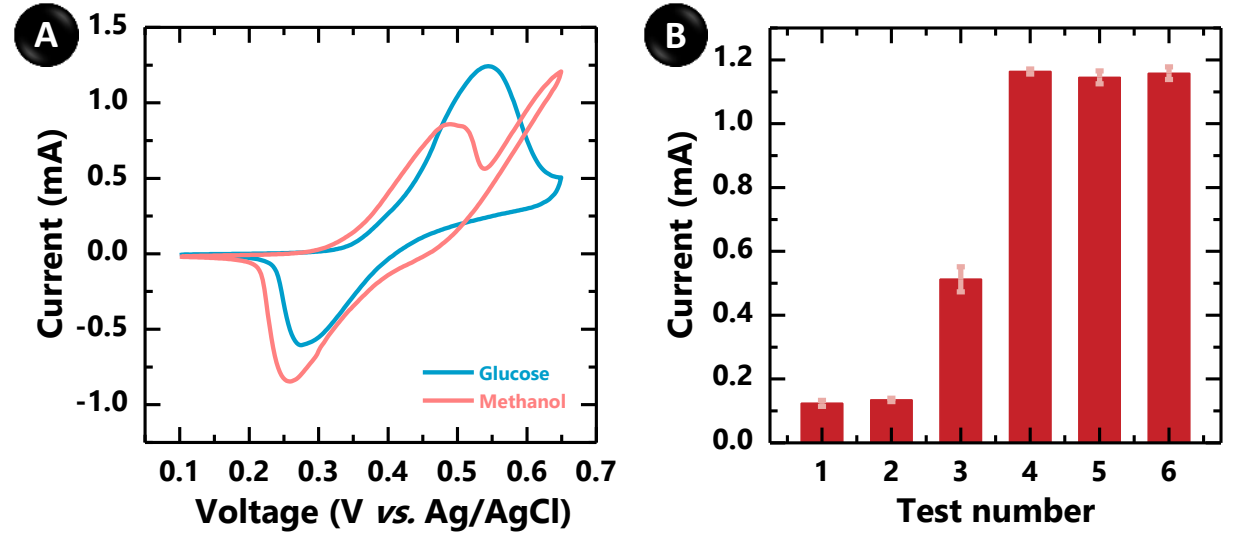

Figure S10. (A) Cyclic voltammograms considering two interferents glucose (5 $\mathrm{mmol} \mathrm{L}^{-1}$ in receptor phase) and methanol $(0.5 \% \mathrm{v} / \mathrm{v}$ in donor phase). (B) Current responses related to the interference test. The evaluated conditions encompassed: (1) blank solution $\left(0.1 \mathrm{~mol} \mathrm{~L}^{-1} \mathrm{NaOH}\right)$ in receptor phase, (2) $5.0 \mathrm{~g} \mathrm{~L}^{-1}$ glucose in donor phase, (3) $5 \mathrm{mmol} \mathrm{L}^{-1}$ glucose in receptor phase, and methanol $0.5 \% \mathrm{v} / \mathrm{v}$ in donor phase without (4) and with glucose at $5.0(5)$ and (6) $10.0 \mathrm{~g} \mathrm{~L}^{-1}(n=3)$.

\section{Long-term monitoring}

We evaluated if the Au-coated SSWM is able to maintain its hydrophobic contact angle, i.e., the same electrodic area over extended periods of time. For this aim, the redox response of $\left[\mathrm{Fe}(\mathrm{CN})_{6}\right]^{4-/ 3-}$ was monitored through cyclic voltammetry over $2 \mathrm{~h}$ in three independent experiments. From Figure S11, an increase of only $1.03 \%$ and $0.92 \%$ in anodic $\left(\mathrm{Ip}_{\mathrm{A}}\right)$ and cathodic peak currents $\left(\mathrm{Ip}_{\mathrm{C}}\right)$, respectively, was observed on the initial currents. This current behavior as a function of time reveals the SSWM was capable of sustaining the contact angle with the solutions. Otherwise, a gradual enhancement in electrode area and, thus in current would be noted in the case of liquid penetration through the MEM holes. Indeed, it is worth mentioning we did not observe any 
liquid passing through the other side of the mesh during the analyses. In addition, the measurements at each time were reproducible, exhibiting a mean relative standard deviation of $0.68 \%$.
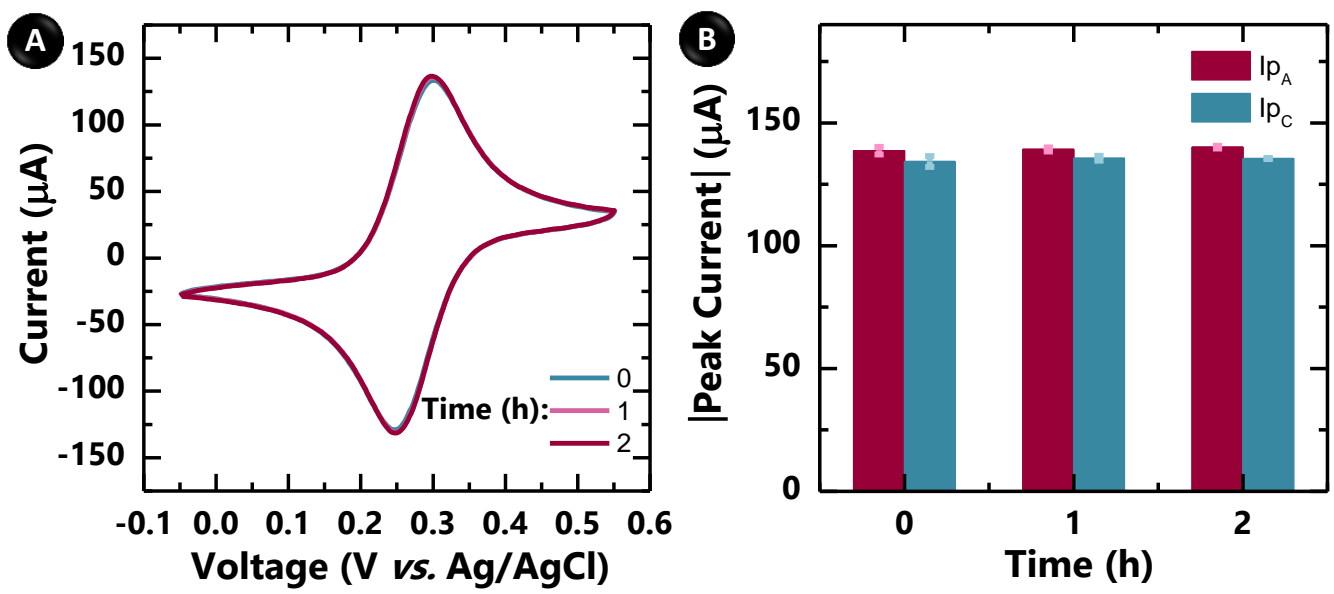

Figure S11. (A) Cyclic voltammetry scans to $2.0 \mathrm{mmol} \mathrm{L}^{-1}\left[\mathrm{Fe}(\mathrm{CN})_{6}\right]^{4-/ 3-}$ over a 2-h batch monitoring utilizing the Au-coated SSWM. (B) Resulting values of $\operatorname{Ip}_{\mathrm{A}}$ and $\operatorname{Ip}_{\mathrm{C}}(n=3)$.

\section{References}

(1) Giordano, G. F.; Vieira, L. C. S.; Gobbi, A. L.; Lima, R. S.; Kubota, L. T. An Integrated Platform for Gas-Diffusion Separation and Electrochemical Determination of Ethanol on Fermentation Broths. Anal. Chim. Acta 2015, 875, 33-40.

(2) Toghill, K. E.; Xiao, L.; Stradiotto, N. R.; Compton, R. G. The Determination of Methanol Using an Electrolytically Fabricated Nickel Microparticle Modified Boron Doped Diamond Electrode. Electroanalysis 2010, 22, 491-500.

(3) Zhao, C.; Shao, C.; Li, M.; Jiao, K. Flow-Injection Analysis of Glucose Without Enzyme Based on Electrocatalytic Oxidation of Glucose at a Nickel Electrode. Talanta 2007, 71, 1769-1773.

(4) Vidotti, M.; Torresi, S. I. C. de; Kubota, L. T. Electrochemical Oxidation of Glycine by Doped Nickel Hydroxide Modified Electrode. Sensors Actuators, B. 2008, 135, 245-249.

(5) Salimi, A.; Roushani, M.; Soltanian, S.; Hallaj, R. Picomolar Detection of Insulin at Renewable Nickel Powder-Doped Carbon Composite Electrode. Anal. Chem. 2007, 79, 7431-7438.

(6) Deng, Y.; Peng, C.; Dai, M.; Lin, D.; Ali, I.; Alhewairini, S. S.; Zheng, X.; Chen, G.; Li, J.; Naz, I. Recent development of super-wettable materials and their applications in oil-water separation. J. Cleaner Prod. 2020, 266, 121624.

(7) Mohns, J.; Künnecke, W. Flow Analysis with Membrane Separation and Time Based Sampling for Ethanol Determination in Beer and Wine. Anal. Chim. Acta 1995, 305, 241-247.

(8) Paixão, T. R. L. C.; Corbo, D.; Bertotti, M. Amperometric Determination of Ethanol in Beverages at Copper Electrodes in Alkaline Medium. Anal. Chim. Acta 2002, 472, 123-131.

(9) Pinyou, P.; Youngvises, N.; Jakmunee, J. Flow Injection Colorimetric Method Using Acidic Ceric Nitrate as Reagent for Determination of Ethanol. Talanta 2011, 84, 745-751.

(10) Silva, C. R.; Gomes, T. F.; Barros, V. A. F.; Zagatto, E. A. G. A Multi-Purpose Flow Manifold for Spectrophotometric Determination of Sulphide, Sulphite and Ethanol Involving Gas Diffusion: Application to Wine and Molasses Analysis. Talanta 2013, 113, 118-122.

(11) Pais, T. F. M.; Vidigal, S. S. M. P.; Tóth, I. V.; Rangel, A. O. S. S. Sequential Injection System for the Enzymatic Determination of Ethanol in Alcoholic Beverages with In-Line Dilution. Food Control 2013, 30, 616-620.

(12) Vidigal, S. S. M. P.; Rangel, A. O. S. S. A Reagentless Flow Injection System for the Quantification of Ethanol in Beverages Based on the Schlieren Effect Measurement. Microchem. J. 2015, 121, 107-111.

(13) Choengchan, N.; Poontong, B.; Mathaweesansurn, A.; Maneerat, N.; Motomizu, S.; Ratanawimarnwong, N.; Nacapricha, D. A "Dual-Acceptor Channel” Membraneless Gas-Diffusion Unit for Simultaneous Determination of Ethanol and Acetaldehyde in Liquors Using Reverse Flow Injection. Anal. Sci. 2018, 34, 169-175.

(14) Ratanawimarnwong, N.; Sinpun, M.; Chankaw, P.; Choengchan, N.; Nacapricha, D. Simple Flow System with In-Line Gas-Diffusion Unit for Determination of Ethanol Employing Hypsochromic Shift of Visible Absorbance Band of Methyl 
Orange. Talanta 2020, 206, 120234.

(15) Zhang, S. L.; Yue, H.; Liang, X.; Yang, W. C. Liquid-Phase Co-Exfoliated Graphene/MoS ${ }_{2}$ Nanocomposite For Methanol Gas Sensing. J. Nanosci. Nanotechnol. 2015, 15, 8004-8009.

(16) Di Pietrantonio, F.; Benetti, M.; Cannatà, D.; Verona, E.; Palla-Papavlu, A.; Fernández-Pradas, J. M.; Serra, P.; Staiano, M.; Varriale, A.; D’Auria, S. A Surface Acoustic Wave Bio-Electronic Nose for Detection of Volatile Odorant Molecules. Biosens. Bioelectron. 2015, 67, 516-523.

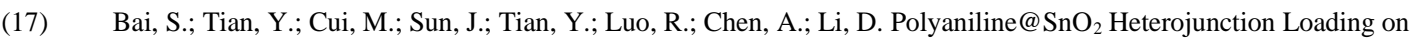
Flexible Pet Thin Film for Detection of $\mathrm{NH}_{3}$ at Room Temperature. Sensors Actuators, B 2016, 226, 540-547.

(18) Paknahad, M.; Bachhal, J. S.; Ahmadi, A.; Hoorfar, M. Characterization of Channel Coating and Dimensions of Microfluidic-Based Gas Detectors. Sensors Actuators, B 2017, 241, 55-64.

(19) Yucel, M.; Akin, O.; Cayoren, M.; Akduman, I.; Palaniappan, A.; Liedberg, B.; Hizal, G.; Inci, F.; Yildiz, U. H. HandHeld Volatilome Analyzer Based on Elastically Deformable Nanofibers. Anal. Chem. 2018, 90, 5122-5129.

(20) Kiaee, M. M.; Maeder, T.; Brugger, J. Inkjet-Printed Composites For Room-Temperature VOC Sensing : From Ink Formulation to Sensor Characterization. Adv. Mater. Technol. 2021, 6, 2000929.

(21) Tao, J.; Wang, X.; Sun, T.; Cai, H.; Wang, Y.; Lin, T.; Fu, D.; Ting, L. L. Y.; Gu, Y.; Zhao, D. Hybrid Photonic Cavity with Metal-Organic Framework Coatings for the Ultra-Sensitive Detection of Volatile Organic Compounds with High Immunity to Humidity. Sci. Rep. 2017, 7, 1-8.

(22) Arakawa, T.; Aota, T.; Iitani, K.; Toma, K.; Iwasaki, Y.; Mitsubayashi, K. Skin Ethanol Gas Measurement System with a Biochemical Gas Sensor and Gas Concentrator Toward Monitoring of Blood Volatile Compounds. Talanta 2020, 219 , 121187.

(23) Mohan, A. M. V.; Windmiller, J. R.; Mishra, R. K.; Wang, J. Continuous Minimally-Invasive Alcohol Monitoring Using Microneedle Sensor Arrays. Biosens. Bioelectron. 2017, 91, 574-579.

(24) Banga, I.; Paul, A.; Sardesai, A. U.; Muthukumar, S.; Prasad, S. M.A.T.H: Methanol Vapor Analytics Through Handheld Sensing Platform. Electrochim. Acta 2021, 368, 137624.

(25) Schleder, G. R.; Padilha, A. C. M.; Acosta, C. M.; Costa, M.; Fazzio, A. From DFT to Machine Learning: Recent Approaches to Materials Science - A Review. J. Phys. Mater. 2019, 2, 032001.

(26) Ouyang, R.; Curtarolo, S.; Ahmetcik, E.; Scheffler, M.; Ghiringhelli, L. M. SISSO: A Compressed-Sensing Method for Identifying the Best Low-Dimensional Descriptor in an Immensity of Offered Candidates. Phys. Rev. Mater. 2018, 2 , 083802 .

(27) Schleder, G. R.; Acosta, C. M.; Fazzio, A. Exploring Two-Dimensional Materials Thermodynamic Stability Via Machine Learning. ACS Appl. Mater. Interfaces 2019, 12, 20149-20157.

(28) da Silva, G. S.; de Oliveira, L. P.; Costa, G. F.; Giordano, G. F.; Nicoliche, C. Y. N.; da Silva, A. A.; Khan, L. U.; da Silva, G. H.; Gobbi, A. L.; Silveira, J. V.; Filho, A. G. S.; Schleder, G. R.; Fazzio, A.; Martinez, D. S. T.; Lima, R. S. Ordinary Microfluidic Electrodes Combined with Bulk Nanoprobe Produce Multidimensional Electric Double-Layer Capacitances Towards Metal Ion Recognition. Sens. Actuators, B 2020, 305, 127482.

(29) Nicoliche, C. Y. N.; De Oliveira, R. A. G.; Da Silva, G. S.; Ferreira, L. F.; Rodrigues, I. L.; Faria, R. C.; Fazzio, A.; Carrilho, E.; De Pontes, L. G.; Schleder, G. R.; Lima, R. S. Converging Multidimensional Sensor and Machine Learning Toward High-Throughput and Biorecognition Element-Free Multidetermination of Extracellular Vesicle Biomarkers. ACS Sens. 2020, 5, 1864-1871.

(30) Casella, I. G.; Cataldi, T. R. I.; Salvi, A. M.; Desimoni, E. Electrocatalytic Oxidation and Liquid Chromatrographic Detection of Aliphatic Alcohols at a Nickel-Based Glassy Carbon Modified Electrode. Anal. Chem. 1993, 65, 3143-3150.

(31) Zhao, C.; Shao, C.; Li, M.; Jiao, K. Flow-Injection Analysis of Glucose Without Enzyme Based on Electrocatalytic Oxidation of Glucose at a Nickel Electrode. Talanta 2007, 71, 1769-1773.

(32) Ccopa Rivera, E.; Yamakawa, C. K.; Saad, M. B. W.; Atala, D. I. P.; Ambrosio, W. B.; Bonomi, A.; Junior, J.; Rossell, C. E. V. Effect of Temperature on Sugarcane Ethanol Fermentation: Kinetic Modeling and Validation Under Very-HighGravity Fermentation Conditions. Biochem. Eng. J. 2017, 119, 42-51.

(33) Silva, C. D.; Corradini, P. G.; Del Colle, V.; Mascaro, L. H.; de Lima, F. H. B.; Pereira, E. C. Pt/Rh/Pt and Pt/Ru/Pt Multilayers for the Electrochemical Oxidation of Methanol and Ethanol. Electrochim. Acta 2020, 354, 136674.

(34) Makin Adam, A. M.; Deng, M.; Zhu, A.; Zhang, Q.; Liu, Q. Facile One-Step Room Temperature Synthesis of PdAg Nanocatalysts Supported on Multi-Walled Carbon Nanotubes Towards Electro-Oxidation of Methanol and Ethanol. Electrochim. Acta 2020, 339, 135929. 